\section{A Flora of Cambridgeshire}

With an Appendix on the Origin and Drainage of the Fens. By Dr. A. H. Evans. Pp. xi+228. (London and Edinburgh: Gurney and Jackson, 1939.) 7s. $6 d$. net.

$A \mathrm{~S}$ there has been no Flora of Cambridgeshire published since Babington's in 1860, a modern flora of the county was much to be desired. Unfortunately this book does not fill the gap adequately, and compares very unfavourably with such a book as the recently published "Flora of Devon". For most species no dates or authorities are given for the record.s. For example, twenty localities are given for Astragalus glycyphyllos, of which fifteen occur in Babington's Flora; the other five are new, but no indication is given of their date or of where the plant still occurs. Relhan's name is cited for the Shelford locality but not for Madingley or Impington, from which places no more recent record than his was known to Babington.

Unfortunately, also, the book contains many errols. Prunus insititia is not a green-twigged woodland plant nor is Juncus bulbosus "not uncommon" but very local. The Cambridge University Herbarium has not been properly consulted, so that many important records are entirely omitted. As examples may be cited Medicago denticulata (a plant not included in the Flora) from near March (Little), Cardamine hirsuta from Chatteris and Apium inundatum from Ditton and Hardwick.

While it is useful to have a record of the author's great personal experience of the plants of the county and while the book contains much useful information, the need for a good modern Flora of Cambridgeshire remains unfilled.

E. F. Warburg.

\section{Essai de meteoropathologie}

Physique, clinique, thérapeutique. Par W. Kopaczewski. Pp. 296. (Paris : J.-B. Baillière et fils, 1939.)

$\mathrm{T}$

HAT certain disorders are caused or influenced by environment, atmospheric conditions, weather, has been surmised from ancient times-for example, ague and swamps, rheumatism and dampness-and in his introduction to this book the author reviews the contradictory evidence thereof. It is also often difificult to disentangle purely environmental from other factors; thus, we now know that swamps generate ague only because they breed the mosquitoes which convey the disease. The author first surveys the physical factors of the air and sun concerned with climate, the physiological details connected with these, and meteorological data. Next, regulation of hody function necessary in a changing environment is dealt with, followed by a discussion of the results upon the body of extreme variations in atmospheric pressure and temperature, exposure to actinic rays, and electric shock. Finally, the treatment of the 'shock' thus caused is considered.

Unfortunately, no information or discussion is included respecting the more subtle influence of minor meteorological disturbances upon body function, such as ordinary variations in barometric pressure, in humidity and in temperature, alterations in direction and force of the wind, and the like, and it is about these that we are still so ignorant. A valu. able section of the book deals with the climate of France, with full meteorological data, and illustrated with fourteen excellent charts.

\section{Aspects of the Calculus of Variations}

Notes by J. W. Green, after Lectures by Hans Lewy. Pp. vi+96. (Berkeley, Calif.: University of California Press ; London: Cambridge University Press, 1939.) 4s. $6 d$. net. 7 HIS little book contains valuable notes taken of in the spring of 1938. The aim of the lecturer was to acquaint the student with a skeleton of the methods, rather than the theorems, of the calculus of variations. Familiarity with the chief methods used in the study of functions of a real variable is assumed.

The notes are divided into six chapters which deal with the derivation of the necessary equations for a continuous function to assume maximum or minimum values; quadratic problems in one variable; the Weierstrassian field theory ; a general theorem on existence of absolute minima; an introduction to harmonic functions and the Dirichlet problem; Plateau's problem and conformal mapping. As the literature on these aspects is either of recent date or is not easily accessible, these interesting notes should be of much use to all students of this subject.

\section{New First Course in the Theory of Equations}

By Dr. Leonard Eugene Dickson. Pp. ix+185. (New York : John Wiley and Sons, Inc.; London : Chapman and Hall, Ltd., 1939.) 10s. 6d. net.

THIS book is founded upon the author's earlier work but is written "in a more expansive style with many illustrations either following or preceding the introduction of new ideas or topics, and with minute attention to details". Proofs have been simplified, so far as possible; more exercises have been added, whilst others have been discarded and additions have been made to the text in order to bring it up to date.

Introductory chapters deal with complex numbers and the elementary theory of roots, after which cubics, quartics and the use of graphs are discussed. Then follow the various methods in use for solving numerical equations, brief discussions of determinants, matrices, symmetric functions, elimination, resultants and discriminants. Finally, the general theory of polygonal constructions is considered analytically. This is a logical sequel to an earlier chapter on some particular impossible constructions by ruler and compasses. The book closes with an appendix on the fundamental theorems of symmetric functions and of algebra.

As the subject naturally touches the borders of so many other fields of study, it is always difficult to render a treatment of the theory of equations in any way complete. Nevertheless, the author has produced an interesting first course which should be quite useful to students as an introduction to the subject. 